\title{
Research
}

\section{Barriers engaging families and GPs in childhood weight management strategies}

\begin{abstract}
\section{Background}

The rapid increase in the prevalence of childhood obesity in recent years has led to inconclusive debate about the most effective way to manage the condition and the most appropriate care setting. Primary care has been suggested as a key site to identify and treat obesity in children.
\end{abstract}

\section{Aim}

To identify children from general practice databases with a body mass index (BMI) categorised as 'obese', and invite them for a primary care consultation and possible referral to a specialist secondary care clinic.

\section{Design and setting}

Targeted screening of GP practice databases for obese children in 12 general practices in Bristol, UK.

\section{Method}

Participating GP practices searched databases for children's BMls which were then screened by the study team to identify obese children ( $\geq 98$ th centile). Practices invited families of obese children to consult their GP with the potential for referral to a specialist clinic. Follow-up data was recorded with respect to: consultations; consultations about child's weight; and referrals to specialist clinic; and other referrals.

\section{Results}

A total of 285 letters inviting families to consult their GP were sent: 134 patients consulted their GP in the follow-up period (minimum 3 months), and 42 of these consultations discussed the child's weight. Nineteen patients received a secondary care referral and six received an alternative weight-management referral.

\section{Conclusion}

The low take-up following the mail-out of an invitation to consult highlights the inherent difficulties of engaging families and their obese children in care pathways that facilitate longterm weight management

\section{Keywords}

child health; mass screening; obesity; primary health care

\section{INTRODUCTION}

The year-on-year increase in childhood obesity prevalence may be levelling off, ${ }^{1}$ but with one in five 11 year olds currently defined as obese, the country remains faced with a potentially huge burden of increased, obesity-associated, morbidity, and early mortality. ${ }^{2}$ This has led to wide-ranging searches for effective policies and interventions to identify and treat this condition. Obesity is a clinical condition with no single associated outcome; the clinical problems are the resultant comorbidities, which include a higher risk of diabetes, cancer, and cardiovascular-related morbidity and mortality in adulthood, ${ }^{3,4}$ and there is evidence that many of the conditions classically considered those of adulthood are manifest in adolescence. 5,6 Because obesity is not a distinct clinical problem, there is no single area of clinical practice that 'owns' the condition. This is evident in the debate about the management of childhood obesity, much of which revolves around the appropriate setting. There is also a recognised paucity of evidence regarding effective methods of treatment. 6,7

The government has made child obesity a health priority, and as part of this strategy they have introduced the National Child Measurement Programme (NCMP), ${ }^{1}$ which annually records the body mass index (BMI) of all children at reception and year 6 . It has also supported MEND, ${ }^{8}$ a community-based weight-management service, and initiated 'Change4Life', 9 a range of printed and

J Banks, programme manager, Academic Unit of Primary Health Care, School of Social and Community Medicine; J PH-Shield, MD, MRCP, FRCPCH, professor of diabetes and metabolic endocrinology, School of Clinical Sciences;

D Sharp, MA, FRCGP, PhD, professor of Primary

health care, Academic Unit of Primary Health Care, School of Social and Community Medicine.

University of Bristol, Bristol.

\section{Address for correspondence}

Jonathan Banks, Academic Unit of Primary Health Care, School Of Social And Community Medicine. interactive resources that support healthier lifestyles for children and families.

The National Institute for Health and Clinical Excellence (NICE) recommends primary care as the main focus for the management of childhood obesity, ${ }^{10}$ and the Department of Health has published a care pathway for children and young people for primary care practitioners. ${ }^{11}$ However, recent research has cast doubt on the suitability of primary care as a resource for effectively tackling childhood obesity. Qualitative studies have shown that practitioners have expressed doubts about the appropriateness of primary care, arguing that their role should be identifying and alerting patients, ${ }^{12}$ and that they lack the resources and expertise to deal with a complex phenomenon with a wide range of potential causes..$^{13}$

This paper examines important issues around identifying obese children and the most appropriate treatment setting. The data derive from the authors' experiences of recruiting patients to the Primary Care-Care Of Childhood Obesity Study (PC-COCO) based in Bristol. ${ }^{14}$ The study is a pilot randomised controlled trial evaluating the transferability of a successful hospitalbased, childhood obesity clinic (the COCO clinic) into primary care. Briefly, the trial design is for obese children referred to the established hospital COCO clinic by their GP, to be recruited and then randomised either to the hospital clinic or to one of two nurseled primary care clinics.

University of Bristol, Canynge Hall, 39 Whatley Road, Bristol, BS8 2PS.

E-mail: Jon.BanksaBristol.ac.uk

Submitted: 21 September 2010; Editor's response: 12 October 2010; final acceptance: 26 November 2010

\section{@British Journal of General Practice}

This is the full-length article (published online 1 Aug 2011) of an abridged version published in print. Cite this article as: Br J Gen Pract 2011; DOI: 10.3399/bjgp11X588466. 


\section{How this fits in}

There is debate about the appropriate setting for the management of child obesity. The National Institute for Health and Clinical Excellence (NICE) has identified primary care as a key site in the identification and treatment of the condition. The data reported here cast doubt as to whether patients and families are willing to engage with primary care on this issue. Furthermore, the data also raise questions about the willingness of primary care practitioners to proactively engage with parents and families on this issue. Without a formal remuneration package and evidence-based care pathways, general practice seems unlikely to be a viable option for universal weightmanagement interventions. Further work is needed to identify how better to engage parents in discussions and action plans to support weight loss in their obese children, especially now that National Child Measurement Programme data are to be routinely fed back to parents by many primary care trusts.

To augment recruitment, the study team obtained ethical approval to contact local general practices to identify and contact parents of children whose BMI indicated they may be obese. This approach was considered a pragmatic solution to trial recruitment, although the research team had little knowledge of how many children's BMls were actually recorded on GP databases. It is not routine practice for GPs to record height, weight, and BMI for schoolaged children. This is partly because recording children's BMI is not part of the general practice Quality Outcomes Framework (QOF) contract which determines payment levels to GPs. ${ }^{15}$ Obesity did feature in the 2006-2007 QOF contract but this was for adults only. ${ }^{15}$ Furthermore, NCMP data are currently not routinely fed back to the child's primary care practice for those measured in reception and year 6 of primary school.

The team also had to take into consideration the response of parents to an unsolicited invitation indicating their child was obese. Children's weight is a sensitive issue that can invoke shame and guilt in parents. ${ }^{16}$ Experience from other studies ${ }^{16-18}$ showed that a sensitively worded invitation letter could be an effective method of contact without causing offence or distress to recipients and their families.

\section{METHOD}

A protocol was developed for running BMI searches on Egton Medical Information Systems (EMIS) databases, and 27 practices were contacted using EMIS systems in NHS Bristol (primary care trust). The study focused on EMIS practices because the team members had more experience of this system, and access to EMIS expertise that would enable them to develop and test a reliable search protocol. Twelve practices agreed to take part. Practice staff ran electronic searches for children and adolescents between the ages of 5 and 16 years with a recorded BMI. These data were exported to an Exce ${ }^{\circledR}$ file with the following fields: practice ID, sex, date of birth, age, BMI, BMI date. The Excel file was securely emailed to the study team members.

The study team excluded all BMIs recorded more than 2 years previously. This cut-off point was based on attaining a balance between the need to identify obese children against the diminishing accuracy of data over time. Using 1990 UK reference growth charts, BMI cut-off points were established that corresponded to the referral criteria for the COCO clinic: $\geq 98$ th centile by age and sex (clinical definition of child obesity ${ }^{10}$ ). Records where BMI was below the cut-off points were deleted, leaving a reduced file of children, which was returned to the practices.

Practice staff then asked GPs to remove children or families from the list that they did not feel were suitable to receive a letter (mainly for clinical and/or social reasons). They also removed patients who had already been referred to the COCO clinic. For the remaining children, the practices sent a letter and information sheet to the families. The letter explained that the practice records showed their child had a high BMI, and invited them to consult their GP who may be able to refer them to the $\mathrm{COCO}$ clinic and study for specialist support. The letter made clear they were not obliged to respond or to consult the GP about their child's weight.

After a minimum period of 3 months, practices were sent a follow-up request for the following data: practice list size; number of children aged between 5 and 16 years; number of patients/families sent letters; number of patients sent a letter and that consulted (to date); number of consultations where the child's weight was discussed; number of children referred to $\mathrm{COCO}$; and number of children referred to alternative weight-management programmes. The data were emailed to the study team members and entered into a database along with the previously recorded data. This enabled the evaluation of the number of 
Table 1. BMls recorded and identified as obese

\begin{tabular}{|c|c|c|c|c|c|}
\hline Stage & Total & Range & Mean & $\begin{array}{c}\% \mathrm{BMI} / \\
\text { recorded BMI }^{\mathrm{a}}\end{array}$ & $\begin{array}{l}\% \text { Obese BMI } \\
\text { /recorded BMI }\end{array}$ \\
\hline 1. Practice list size age $5-16$ years ${ }^{c}$ & 15845 & $948-1912$ & 1320.4 & - & - \\
\hline 2. BMI recorded $<2$ years ${ }^{d}$ & 1843 & $64-415$ & 153.6 & 11.6 & - \\
\hline 3. Obese $\mathrm{BMI} \geq 98$ th centile & 363 & $17-66$ & 30.3 & - & 19.7 \\
\hline 4. BMI $\geq 98$ th centile/sent GP letter & 285 & $11-44$ & 23.8 & - & 15.5 \\
\hline \multicolumn{6}{|c|}{$\begin{array}{l}\text { Percentage denominator is number aged 5-16 years in total practice list. }{ }^{b} \text { Percentage denominator is number } \\
\text { of BMls recorded }<2 \text { years in 5-16 years age range. }{ }^{c} \text { Recorded between } 25 \text { March } 2009 \text { and } 8 \text { June } 2009 . \\
{ }^{d} \text { Recorded between } 24 \text { October } 2008 \text { and } 12 \text { December 2008, only BMls recorded within } 2 \text { years of database } \\
\text { search date. }\end{array}$} \\
\hline
\end{tabular}

children referred to the COCO clinic following receipt of a letter; the proportion of those receiving a letter who consulted their GP; and the number who discussed their child's weight.

\section{RESULTS}

Twenty-seven practices in NHS Bristol were contacted and asked to undertake the database searches. Twelve practices agreed to participate. The results are presented in two tables: the first documents the initial searches of practice databases and the identification of children with a BMI $\geq 98$ th centile, and the second contains the consultation data retrieved at least 3 months after the patient letters had been sent out.

Table 1 shows the total practice list size for the $5-16$ years age group $(n=15845)$ and the number of recorded BMIs ( $n=1843$ ) for the 12 practices, indicating that $11.6 \%$ in this age range had a BMl recorded in the last 2 years on their practice database. From this group, 363 were identified whose BMI was 298th centile by age and sex. GPs then identified which families were not suitable to receive the letter; 285 families were sent an invitation letter by their practice.

The data in Table 2 were collected after a minimum period of 3 months. These data show the degree to which mailing families was successful, by tracking the number who consulted, discussed weight at a consultation, and were referred to the clinic and/or referred to other programmes. Just under half of those sent letters consulted their GP $(n=134,47 \%)$. However, there is a steep decline in the number who actually

\section{Table 2. Consultations and referrals}

\begin{tabular}{lcccc} 
Stage & Total & Range & Mean & $\begin{array}{c}\text { \% Consulted and referred/ } \\
\text { sent letter by GPa }\end{array}$ \\
\hline 5. Number consulted & 134 & $1-24$ & 11.2 & 47.0 \\
\hline 6. Weight discussed & 42 & $1-7$ & 3.5 & 14.7 \\
\hline 7. COCO referral & 19 & $0-4$ & 1.6 & 6.7 \\
\hline 8. Other referral & 6 & $0-3$ & 0.5 & 2.1 \\
\hline
\end{tabular}

a Percentage denominator is the number of letters sent to families ( $\mathrm{n}=285$ ). engaged in a weight-related consultation; only $42(14.7 \%)$ were recorded in the GP notes as discussing their child's weight following receipt of the invitation letter. The next stage shows a further large reduction to the number of COCO referrals, with only 19 patients from a possible 285 (6.7\%), receiving a referral. The number receiving other referrals was even lower, with only six (2.1\%) children being referred to other types of weight-management programmes.

\section{DISCUSSION}

\section{Summary}

While the study methodology identified a sufficiently large group of obese children and adolescents to make this a worthwhile exercise, the results highlight the problems inherent in engaging children and families in weight-management services. Fewer than one in six families that were invited actually engaged in a weight-related consultation with their GP, and fewer than one in 11 of all those sent an invitation letter to discuss weight were actually referred for any weightmanagement service. In consideration of this low take-up, the following points can be made.

First, as noted earlier, weight, especially children's weight, is a sensitive issue that can be a very difficult area for children, parents, GPs, and other healthcare workers to discuss. When presented with an opportunity to discuss the matter with their GP, only a small proportion of those sent letters did so. This is particularly striking, as the letters offered the potential for a further care pathway via a specialist clinic comprising medical, dietary, and exercise intervention; such a comprehensive care pathway is almost unique in the UK healthcare system, but for the majority of recipients this offer was not attractive. There may be a number of reasons for this, including: non-recognition of the child's obesity, and the parent and/or child lacking motivation. There is a possibility that families reacted negatively to the letter, although informal feedback from participating practices indicated this had not been an issue at practice level.

Second, the disjuncture between the total who consulted $(n=134)$ and those who consulted about weight $(n=42)$ is striking. The most likely explanation for this is that families consulted their GP about something other than concerns about the child's weight. However, as the family had been invited to consult about their child's weight and the invitation was recorded in the patient record, there is an argument that this represents a missed opportunity by the 
healthcare professional, usually the GP, to raise the issue. This opportunity will, of course, depend on the nature of the condition with which the patient presents; severe acute illness would limit the opportunity to introduce the issue of weight. However, the overall picture presented here does reaffirm research literature indicating that GPs are reluctant to engage in discussions regarding weight management for children.

\section{Strengths and limitations}

The cornerstone of the study data is the letter sent by the GP practices to families of children with high BMls. This was not a letter inviting families to take part in a study but a letter inviting the family to discuss their child's weight with their GP. It must be acknowledged that had the letter focused directly on the research project, this may have increased take-up. However, inviting families to consult their GP was consistent with the study's recruitment strategy, with the GP assessing eligibility and suitability for referral to the COCO clinic. The response to the letter goes beyond the efficacy of the recruitment strategy; it provided valuable data on the relationship between child obesity, primary care, and the patient community. This is a key issue in the debate about how and where childhood obesity is managed.

This is a small dataset, which limits generalisability. The BMI data held at GP practices was partial; it is not known why some children had a BMI recorded and others did not. Consultations recording a discussion about weight were captured from the patient notes but the extent to which weight was discussed and not formally recorded is not known.

The community-based MEND programme was running concurrently in Bristol, but as it was targeting a different patient population (<98th centile) it is not thought likely that the programme will have impacted on the study.

\section{Comparison with existing literature}

It is known from previous research that parents of overweight children find it difficult to seek help from a health professional, ${ }^{19}$ and it is also known that parents have difficulty recognising overweight or obesity in their children. ${ }^{19,20}$ Research also points to some parents not recognising or not accepting overweight and obesity in their child as a health problem that needs attention. ${ }^{21}$ The letters sent only produced a consultation rate below 15\%, which resonates with these findings. It would be expected that those parents who are unsure about how to deal with their child's weight would be prompted by the letter, but the study data suggest something closer to resistance to addressing the issue with primary care practitioners.

On the practitioner side, there is recognition that primary care has a role to play in managing childhood obesity, 12,22 but as pointed out in the introduction, there is also a significant degree of scepticism that relates to the time and resources available to primary care practitioners to effectively manage this issue. ${ }^{13,22,23}$ An Australian study found that GPs were reluctant to engage with child obesity because of limited referral options. ${ }^{24}$ The present data indicate that even with an available referral pathway there was a reluctance by GPs to engage in weightrelated discussions with children and their families.

\section{Implications for practice and research}

The overall number of children aged 5-16 years with a BMI recorded in the GP record in the previous 2 years was low $(11.6 \%)$. There is no formal requirement or inducement for GP practices to record children's BMI, yet it is known that obesity in childhood leads to significant morbidity in adult life. By not recording these data, there is little likelihood that GPs and other members of the primary care team will ask about weight, diet, and exercise when consultations are taking place for other reasons. It is also known that health professionals are poor at identifying children with a BMI in the overweight and obese range. ${ }^{25}$ It must be acknowledged that it is not known why these particular patients had their BMls recorded and whether this is skewed toward particular patient subgroups; for example, those with manifest comorbidities. However, the observed prevalence of obese children is close to the percentage prevalence of obesity in year 6 children in Bristol from the latest NCMP data, at $17.9 \%$. $^{1}$ The data do indicate the potential for BMI data to act as a trigger for GPs and other practice healthcare professionals to consider raising the issue of weight and offering advice or even referral. Although the experience of this study was not successful in terms of boosting referral to the trial, it does highlight a potentially untapped resource in terms of identifying children with a pressing health need.

The results of this study highlight the difficulties inherent in engaging families and obese children in care pathways that facilitate long-term weight management. The strategy to contact families of children 
with BMls in the obese range was not successful, even with the accompanying COCO clinic support package as an inducement. It can also be argued that the results raise questions about the likely effectiveness of the NCMP feedback strategy. The NCMP now instructs primary care trusts to routinely feed back measurement results to families along with 'Change4Life' support literature. ${ }^{9}$ The experience of this study suggests that this strategy may have limited success, and the authors argue that future research needs to develop innovative care pathways that engage both families and primary care practitioners. While it is recognised that there is a need for high-quality research into methods of weight management for children, the experience of this study shows that there is an accompanying need to explore how to engage parents, children, and primary healthcare professionals in recognising obesity and the need to actively manage the condition. 


\section{REFERENCES}

1. The Information Centre for Health and Social Care. National child measurement programme, 2008/09 school year. Leeds: The Information Centre for Health and Social Care, 2009.

http://www.ic.nhs.uk/webfiles/publications/ncmp/ncmp0809/NCMP_England_ 2008_09_school_year_report_2.pdf (accessed 29 Mar 2011).

2. Department for Business Innovation and Skills. Foresight. Tackling obesities future choices. http://www.bis.gov.uk/foresight/our-work/projects/currentprojects/tackling-obesities (accessed 29 Mar 2011).

3. Bibbins-Domingo $\mathrm{K}$, Coxson $\mathrm{P}$, Pletcher $\mathrm{M}$, et al. Adolescent overweight and future adult coronary heart disease. N Engl J Med 2007; 357(23): 2371-2379.

4. Brown $\mathrm{S}$. The heart of the matter: the case for taking childhood obesity seriously. Br J Gen Pract 2005; 56(530): 710-717.

5. Haines L, Kay Chong Wan, Lynn R, et al. Rising incidence of type 2 diabetes in children in the United Kingdom. Diabetes Care 2007; 30(5): 1097-1101.

6. Sabin MA, Shield JPH. Childhood obesity. Front Horm Res 2008; 36: 85-96.

7. Oude Luttikhuis $H$, Baur $L$, Jansen $H$, et al. Interventions for treating obesity in children. Cochrane Database Syst Rev 2009; (1): CD001872.

8. Sacher PM, Kolotourou M, Chadwick PM, et al. Randomized controlled trial of the MEND program: a family-based community intervention for childhood obesity. Obesity 2010; 18 Suppl 1: S62-S68.

9. Change4Life.

http://www.nhs.uk/Change4Life/Pages/default.aspx?gclid=CNOf6dPL350CFa Bb4wodPU-xOA (accessed 29 Mar 2011).

10. National Institute for Health and Clinical Excellence. Obesity: the prevention, identification, assessment and management of overweight and obesity in adults and children. London: NICE, 2006. http://www.nice.org.uk/guidance/CG43 (accessed 29 Mar 2011)

11. Department of Health. Obesity care pathway and your weight, your health. London: Department of Health, 2006.

http://www.dh.gov.uk/PublicationsAndStatistics/Publications/PublicationsPolic yAndGuidance/PublicationsPolicyAndGuidanceArticle/fs/en?CONTENT_ID=41 34408\&chk=Sq/wNd laccessed 29 Mar 2011)

12. Walker $\mathrm{O}$, Strong $\mathrm{M}$, Atchinson $\mathrm{R}$, et al. A qualitative study of primary care clinicians' views of treating childhood obesity. BMC Fam Pract 2007; 8: 50-57.

13. Turner KM, Shield JPH, Salisbury C. Practitioners' views on managing childhood obesity in primary care: a qualitative study. $\mathrm{Br} J$ Gen Pract 2009: 59(568): 856-86.

14. Sharp D, Salisbury C. Evaluating the transferability of a successful, hospitalbased, childhood obesity clinic into primary care: a pilot study. NIHR number PB-PG-0706-10090. Bristol: University of Bristol, 2007.

http://clinicaltrials.gov/ct2/show/NCT00536536 laccessed 29 Mar 2011).

15. The Information Centre for Health and Social Care. Quality and Outcomes Framework achievement data 2008/2009. Leeds: The Information Centre for Health and Social Care, 2009. http://www.ic.nhs.uk/webfiles/Q0F/200809/QOF\%20Achievement\%20and\%20Prevalence\%20Bulletin\%202008-09.pdf laccessed 29 Mar 2011).

16. Grimmett C, Croker H. Carnell S, et al. Telling parents their child's weight status: psychological impact of a weight screening programme. Pediatrics 2008; 122(3): e682-688.

17. Johnson SB, Pilkington LL, Lamp C, et al. Parent reactions to a school-based body mass index screening program. J Sch Health 2009; 79(5): 216-223.

18. Kubik MY, Fulkerson JA, Story M, et al. Parents of elementary school students weigh in on height, weight, and body mass index screening at school. J Sch Health 2006; 76(10): 496-501

19. Stewart L, Chapple J, Hughes AR, et al. Parents' journey through treatment for their child's obesity: a qualitative study. Arch Dis Child 2008; 93(8): 35-39.

20. Jeffery AN, Voss LD, Metcalf BS, et al. Parents' awareness of overweight in themselves and their children: cross-sectional study with a cohort (EarlyBird 21). BMJ 2005; 330(7481): 23-24

21. Eckstein KC, Mikhall LM, Ariza AJ, et al. Parents' perceptions of their child's weight and health. Pediatrics 2006; 117(3): 681-690.

22. Gerner B, McCallum Z, Sheehan J, et al. Are general practitioners equipped to detect child overweight/obesity? Survey and audit. J Paediatr Child Health 2006; 42(4): 206-211.

23. Jelalian E, Boergers J, Sloan Alday C, Frank R. Survey of physician attitudes and practices related to pediatric obesity. Clin Pediatr 2003; 42(3): 235-245.

24. King LA, Loss JHM, Wilkenfeld RL, et al. Australian GPs' perceptions about child and adolescent overweight and obesity. The Weight of Opinion study. $\mathrm{Br}$ J Gen Pract 2007; 57(535): 124-129.

25. Smiths SM, Gately P. Rudolf M. Can we recognise obesity clinically? Arch Dis Child 2008; 93(12): 1065-1066. 